\title{
Determinants of and Barriers to the Adoption of Activity-Based Costing for Manufacturing SMEs in South Africa's Emfuleni Municipality
}

\author{
Rosebud Rundora \\ Faculty of Management Sciences, Accountancy Department \\ Vaal University of Technology, Vanderbijlpark. South Africa \\ E-mail: rosebudr@vut.ac.za \\ Jacob Selesho \\ Faculty of Management Sciences, Vaal University of Technology, \\ Vanderbijlpark, South Africa \\ jacobs@vut.ac.za
}

Doi:10.5901/mjss.2014.v5n3p30

\begin{abstract}
Activity-based costing is an accounting system instituted by large firms for allocating costs to specific products based on the resources that they consume. Since its inception, there have been significant benefits derived from the implementation of activity-based costing systems by large firms, however its acceptance by the small firms have prompted some doubts among its non-user. While some small firms have accepted the use of activity-based costing systems, this paper seeks to establish the barriers that foster negative perception among the non-user. This paper reports on the study of 48 small manufacturing firms in the area of southern Gauteng, South Africa, which made use of the quantitative research approach, while the survey method was chosen for data collection in the selected small manufacturing firms operating in the area. These firms were selected from the Emfuleni municipality in the southern region of Gauteng. The respondents were requested to respond to the questionnaire on their perceptions and experiences regarding the application of activity-based costing. They were asked to indicate the barriers that impede their adoption of ABC. Furthermore, non-users were asked to indicate their reasons for not having adopted the system. The paper reveals the differences in the perception of $A B C$ users and non-users, even though the study found that four of eleven 11 barriers of implementing $A B C$ are rated significantly higher by the non-users. The highest ranking barrier among other non-users was a lack of knowledge concerning $A B C$. Other non-user raised the challenge in defining cost drivers as well as identifying activities. Finally, at the end potential recommendations of the study are made for future research.
\end{abstract}

Keywords: SME's, Activity-Based Costing, Traditional Costing, Barriers, Determinants.

\section{Introduction}

Global competition is leading all kinds of businesses towards a renewed commitment to high levels of competitiveness in their business operations. Small medium enterprises (SME) are the important drivers of transformation needed for any economy as well as the growth. It is also important to acknowledge the contribution made by the SME firms in creating employment opportunities and contribute to the national gross domestic product (GDP). Elliot and Boshoff (2007) argue that Small firms ensure income stability, enhance economic growth, upgrade human capital and contribute to poverty alleviation.

Despite the significant roles played by small firms in an economy, their growth is largely constrained or hindered by factors such as lack of access to appropriate technology, limited access to international markets, lack of finance, lack of management skills and existence of laws and regulations that restrain their operations (Abor \& Quartey 2010).

In order for small firms to survive in today's competitive environment, they should have a proper costing system in place. Decades ago many firms were using the traditional costing systems that are volume based and do not take the activities that go into manufacturing the product into consideration (Johnson \& Kaplan; 1987). These traditional costing systems were unable to provide accurate cost information for products or services. Hence, a new system known as Activity-based costing (ABC) was developed to offer a solution to the short-comings of the traditional costing systems (Cooper \& Kaplan; 1991). However, studies show that even though the ABC system was developed years back, many small firms are still using these old methods of costing their products (Gunasekaran \& Singh: 1999; Mersereau: 2007 and 
Drury: 2008). There are so many reasons attributed to their reluctance to adopting the ABC system, some of which are, the lack of knowledge, lack of finance, lack of education and training.

Against this background it is vital to investigate the challenges experienced by the small firm towards the adoption of $A B C$, establish the barriers that are impeding the adoption and implementation of $A B C$ by these small firms. Gunasekaran and Singh (1999) state that despite the significant opportunities and benefits associated with ABC small manufacturing firms have been reluctant to adopt this system.

\section{Theoretical Rationale}

Activity-based costing is a system that constitutes a reliable system of providing accurate cost information (Cooper \& Kaplan 1989). It offers a solution to the short-comings of the traditional costing systems. ABC was developed in 1988 by Kaplan and Cooper the professors from Harvard Business School. Their main aim was to provide an alternative approach for assigning overheads to products and computing product cost. ABC is a system that allocates resource costs to products based on the activities which are the factors causing work and incurring costs used by the products or customers (Turney 1996). Kaplan (1988) posits that product costs based on ABC system are claimed to have more accuracy than those of the traditional costing systems. Mishra and Vaysman (2001) confirmed that ABC has become the accepted remedy for the significant limitations of traditional costing systems. Information derived from $A B C$ empowers managers to make better decisions. Product costs reported by the $A B C$ system are more accurate than those by the traditional costing systems in many situations including diversity of product size or volume. According to Morrow and Ashworth (1994), ABC helps management to have an understanding of the organization's activities, their costs and how they link together to form a chain of value-creating activities for an organization. Furthermore, $A B C$ does not only provide a basis for calculating more accurate product costs but is also used as a mechanism for managing costs.

However, ABC system has got its limitations. It is a very expensive system to implement and operate. According to Rajasekaran and Lalitha, (2010), it is difficult to measure cost drivers; the requirement of more activities and more cost pools leads to misidentification of costs and huge measurement errors.

\subsection{Hypothesis}

Since the firms that have implemented $A B C$ have more practical experiences than the firms who did not adopt $A B C$, it can be hypothesized that the perceptions regarding the barriers of $A B C$ are different between these two groups. The hypothesis is stated as "there are no mean differences between the perception on the barriers impeding the adoption of $A B C$ of businesses who implemented $A B C$ and those who did not".

\section{Research Design and Methodology}

\subsection{Data collection}

The data was collected by means of structured questionnaires that were hand-delivered to the owners/managers/finance staff of small manufacturing firms operating in the Southern Gauteng region. The cover letter outlined the purpose of the study as well as ensuring anonymity and confidentiality of the responses.

For this study, a convenience sample, sometimes called grab or opportunity sampling was used. Its main disadvantage is that it is classified as non-probability sampling, because elements in the population are included since they are easily and conveniently available, but not necessarily representative of the population (Maree, 2011). Therefore, convenience sampling is the method of choosing items in an unstructured manner from the population frame. However, it is chosen because respondents can be reached easily, costs can be kept to a minimum and most importantly, it is useful in exploratory research to get a quick approximation of the truth (Maree, 2011). A sample of 80 small manufacturing firms operating within the Southern Gauteng Region was selected according to a list obtained from the Vaal Information Directory (2013) and from the Yellow Pages (2013).

In total, 48 respondents completed the questionnaire, which represents a response rate of $60 \%$, where 16 and 32 respondents indicated that they have adopted/ not-adopted ABC, respectively. (Note that only 30 of the 32 respondents completed Section E of the questionnaire.) 


\subsection{Measurement instrument}

The questionnaire was divided into five sections; Section A focuses on the firms' profile; Section B focuses on the perceived benefits derived from implementing $A B C$, Section $C$ focuses on the perceived barriers impeding the respondents' adoption of $A B C$, Section $D$ concentrates on the practical issues of $A B C$ within small companies and Section $E$ refers to those companies that have not implemented $A B C$ and the reasons for not adopting $A B C$. The questionnaire comprised a five-point Likert scale and the respondents were instructed by the researcher during the administration of the questionnaire to circle the most suitable answer. The scale ranged from 1 to 5 as follows:

1. Strongly disagree;

2. Disagree;

3. Neutral;

4. Agree and

5. Strongly agree.

\subsection{Data analysis}

In respect of the statistical analysis, the means (averages) of the perceived barriers for the firms who implemented $A B C$ are compared with the firms who did not adopt ABC. The t-test, which is suitable for smaller samples (Swanepoel, Swanepoel, Van Graan, Allison \& Santana, 2010) was performed to determine whether the differences between these two independent group's means are significant. Since Microsoft Excel was used, the F-test was first performed to determine whether a t-test, assuming equal variances, or a t-test, assuming unequal variances, should be run (Arthur, 2009). A null-hypothesis is stated that there is no difference between the means of the two sets of data. A significant level of $\rho<\alpha=0.05$ is used, implying that $p<0.05$ assumes unequal variances and $p>0.05$ assumes equal variances. Since this is a two-sided approach, the two-tail values were used in the statistical analysis.

The t-test was based on the following significant levels, where $\rho<\alpha=0.01$ and $\alpha=0.05$, respectively (two-tailed) implying that there is overwhelming and strong evidence, respectively, that the null-hypothesis should be rejected in favor of the alternative hypothesis. Where $p>a=0.05$, the null-hypothesis will not be rejected since there is weak or no evidence to accept the alternative hypothesis (Wegner, 2007).

\subsection{Validity and reliability}

Cronbach's Alpha coefficient is typically equated with internal consistency. The Cronbach's Alpha is interpreted as a coefficient Alpha and its value ranges from 0 to 1. Cohen, Manion \& Morrison (2007) advises that when calculating Cronbach's reliability coefficient, reliabilities less than 0.6 are considered poor, reliabilities within 0.7 ranges are considered acceptable and those coefficients over 0.8 are considered good. For the purpose of the current study the Cronbach alpha coefficient rate are reported in as follows:

- $\quad$ Barriers of $A B C$ implementation $=0,71$

- Practical experiences with $A B C=0,80$

- Reasons for not implementing $A B C=0,74$

- The discriminant validity of the constructs was established, all pairs of the constructs revealed adequate levels of discriminant validity.

- The scale reliability provided support for acceptable internal consistency within the constructs; satisfying convergent validity

\section{Findings and Discussions}

The findings of the questionnaire are presented under the following three topics, firstly the difference in perceptions on the barriers to $A B C$ adoption between firms who implemented $A B C$ and those who did not, and secondly, the report on the experiences faced by the firms who implemented $A B C$ and the reasons given by the remaining firms for not adopting $A B C$. 


\subsection{Difference in perceptions on the barriers to $A B C$ adoption}

Table 1: Statements regarding the barriers $A B C$

\begin{tabular}{|c|l|}
\hline Statements & \\
\hline B1 & High cost of implementing ABC \\
B2 & Resistance to change \\
B3 & Involves a great deal of work \\
B4 & It is time consuming \\
B5 & Lack of top management support \\
B6 & Lack of cooperation and commitment among departments \\
B7 & Lack of knowledge concerning ABC \\
B8 & Problems in defining cost drivers \\
B9 & Problems in identifying activities \\
B10 & High cost of consultations \\
B11 & A higher priority of other changes or projects \\
\hline
\end{tabular}

Source: Own research

Table 2 indicates that the null-hypothesis should be rejected, implying that there is a significant difference between the perception of $A B C$ users and non-users, where the non-users agree more (higher mean scores) than the $A B C$ users that barriers impeding the adoption of $A B C$ are: $A$ lack of knowledge concerning $A B C(B 7)$; problems in defining cost drivers (B8); problems in identifying activities (B9); and there is a higher priority of other changes or projects (B11). For the rest of the statements in Section B, the null-hypothesis should not be rejected, implying that there is no difference between the perceptions of $A B C$ users and non-users.

Table 2: Difference between users' and non-users' perceptions of the barriers of $A B C$

\begin{tabular}{|lccccccccccc|}
\hline Users ( $\mathbf{n = 1 6 )}$ & $\mathbf{B 1}$ & $\mathbf{B 2}$ & $\mathbf{B 3}$ & $\mathbf{B 4}$ & $\mathbf{B 5}$ & $\mathbf{B 6}$ & $\mathbf{B 7}$ & $\mathbf{B 8}$ & $\mathbf{B 9}$ & $\mathbf{B 1 0}$ & $\mathbf{B 1 1}$ \\
Mean & 4.375 & 4.000 & 4.438 & 4.250 & 2.875 & 3.125 & 3.313 & 2.875 & 2.875 & 4.375 & 2.938 \\
Std dev. & 0.885 & 0.730 & 0.814 & 0.775 & 1.147 & 1.025 & 0.793 & 0.885 & 0.885 & 0.806 & 0.250 \\
$\begin{array}{l}\text { Non-users ( } \mathbf{n}=32) \\
\text { Mean }\end{array}$ & & & & & & & & & & & \\
Std dev. & 4.656 & 4.063 & 4.500 & 4.625 & 3.281 & 3.281 & 4.031 & 3.781 & 3.813 & 4.625 & 3.719 \\
\hline $\begin{array}{l}\text { F-test } \\
\text { p-value }\end{array}$ & 0.483 & 0.504 & 0.508 & 0.492 & 0.813 & 0.772 & 0.595 & 0.491 & 0.535 & 0.492 & 0.523 \\
t-test & & & & & & & & & & & \\
p-value & 0.002 & 0.040 & 0.013 & 0.016 & 0.051 & 0.089 & 0.086 & 0.003 & 0.009 & 0.010 & 0.002 \\
Significance & 0.250 & 0.761 & 0.781 & 0.092 & 0.163 & 0.557 & 0.001 & 0.001 & 0.001 & 0.268 & 0.000 \\
\hline
\end{tabular}

** Significant at $5 \%$ and ${ }^{* * *}$ significant at $1 \%$ (two-tailed)

Source: Own calculations

\subsection{Implementation issues of $A B C$ and reasons for not implementing $A B C$}

Table 3 exhibits the ranking of eight statements posed to the respondents regarding some implementation issues of $A B C$, where a range from 1 to 5 was used indicating "strongly disagree" to "strongly agree". These eight statements were rated in a relative narrow range, from 3.53 to 2.53 , the highest and the lowest agreed statements. This narrow range, with an average close to 3 on the Likert scale, is evidence that the respondents' opinions are to a great extent "neutral" in respect of these statements. Nevertheless, the highest-ranked statement is that ABC's benefits have exceeded the cost of implementing it. 
Table 3: Ranking of practical issues of $A B C(n=16)$

\begin{tabular}{|c|c|c|c|}
\hline Rank & & Mean & $\begin{array}{l}\text { Std } \\
\text { dev. }\end{array}$ \\
\hline 1 & $A B C$ benefits have exceeded the cost of implementing it & 3.53 & 0.52 \\
\hline 2 & Top management has provided adequate resources to $A B C$ initiative & 3.40 & 1.30 \\
\hline 3 & $A B C$ is tied to the competitive strategies of the business & 3.40 & 0.63 \\
\hline 4 & The top management are/ were committed to use the $A B C$ information as the basis for decision making & 3.33 & 0.98 \\
\hline 5 & Compensation systems in the company have been designed to motivate employees to implement $A B C$ & 2.93 & 0.59 \\
\hline 6 & There has been consensus about the objectives and aims of $A B C$ & 2.93 & 0.96 \\
\hline 7 & $\begin{array}{l}\text { The objectives and purpose of the ABC implementation were clearly stated and understood by both } \\
\text { designers and users }\end{array}$ & 2.87 & 0.92 \\
\hline 8 & Adequate training is/was provided for implementing $A B C$ & 2.53 & 0.52 \\
\hline
\end{tabular}

Source: Own research

Table 4 exhibits the ranking of 12 statements posed to the respondents regarding the reasons why their firms did not adopt $A B C$, where a range from 1 to 5 was used to indicate "strongly disagree" and "strongly agree". The high means of the first four statements indicate that respondents highly agreed that $A B C$ is too expensive, there is a lack of adequate systems, it's too detailed/time consuming and they have a lack of skills/knowledge regarding ABC. These findings are in line with the findings of Needy, Nachtmann, Roztocki and Warner (2003) and Raiborn and Kinney (2009).

Table 4: Ranking of reasons for not adopting $A B C(n=30)$

\begin{tabular}{|c|l|c|c|}
\hline Rank & & Mean & Std dev. \\
\hline 1 & Too expensive to implement & 4.87 & 0.35 \\
2 & Lack of adequate systems & 4.57 & 0.50 \\
3 & Too detailed, time consuming & 4.50 & 0.51 \\
4 & Lack of skills/ knowledge of ABC & 3.80 & 0.85 \\
5 & Difficulty defining cost pools, cost drivers & 3.23 & 0.63 \\
6 & Difficulty identifying suitable cost drivers & 3.20 & 0.55 \\
7 & Difficulty with data & 3.20 & 0.66 \\
8 & Difficulty configuring ABC with other systems & 3.13 & 0.35 \\
9 & Inadequate marketing of ABC & 3.03 & 0.56 \\
10 & Satisfaction with the current system & 2.63 & 0.93 \\
11 & Does not add value & 2.43 & 0.73 \\
12 & Negative publicity about ABC & 2.23 & 0.77 \\
\hline
\end{tabular}

\section{Source: Own research}

\section{Summary of Findings and Conclusions}

The findings in the research highlight a number of issues concerning the application of $A B C$ and the barriers to $A B C$ adoption by small manufacturing companies in the Emfuleni local municipality. These are summarized as follows:

- Regarding the differences in the perception of $A B C$ users and non-users, the study found that the following four of 11 barriers of implementing $A B C$ are rated significantly higher by the non-users, namely: A lack of knowledge concerning $\mathrm{ABC}$; Problems in defining cost drivers; Problems in identifying activities; and That there is a higher priority of other changes or projects (Table 2).

- The eight statements posed to $A B C$ users regarding their experience of some practical issues of $A B C$ reveal that the statements were rated in a relatively narrow range with an average close to the middle of the Likert scale is evident that the respondents' opinions are to a great extent "neutral" in respect of these statements. Nevertheless, the highest ranked statement is that ABC's benefits have exceeded the cost of implementing it (Table 3).

- The ranking of 12 statements posed to the non-users of $A B C$ revealed that respondents highly agreed that $A B C$ is too expensive, there is a lack of adequate systems, it's too detailed/time consuming and they have a 
lack of skills/knowledge regarding $A B C$.

\section{Summary and Practical Implications}

This study concluded that:

- The main concern is that $A B C$ is per se expensive to implement. It is recommended that firms do a costbenefit analysis of $A B C$ to enable them to decide whether it will be worth implementing the system or not.

- Most respondents are failing to adopt $A B C$ because they do not possess adequate skills required to implement ABC;

- There is lack of knowledge regarding $A B C$, therefore, training and education should be provided in order for companies to have an idea of what this system is all about.

- There should be adequate marketing of $A B C$ so that those companies that do not have an idea of what it is might gain an insight into what $A B C$ is all about;

It is expected that the results might differ if a broader study were to be undertaken that covered all the small manufacturing firms and if this was extended to cover the greater Gauteng region. Research could be carried out into other small firms that are not into manufacturing only but service industries or retail industries. Further research could be carried out to investigate the impact of $A B C$ on the financial performance of small firms

\section{References}

Abor, J. and Quartey, P. 2010. Issues In SME Development In Ghana And South Africa. International Research Journal of Finance and Economics, 39: 218-228.

Arthur, J. 2009. To test two samples assuming equal variances in Excel. [Online] Available at http://www.qimacros.com/qiwizard/t-test-twosample.html Accessed: June 22nd, 2010.

Cohen, L.; Manion, L. \& Morrison, K. 2007. Research Methods in Education. London:Routledge Falmer Publishers.

Cooper, R., \& Kaplan, R. S., 1998. The Design of management Systems: Text and Cases. Second Edition. Prentice Hall International, INC.

Cooper, T., \& Kaplan. 1991. Profit priorities from activity-based costing. Harvard Business Review, May/ June, 69 (3):130-135.

Drury, C. 2008. Management and cost accounting. $7^{\text {th }}$ ed. South Western Cengage Learning.

Elliot, R. \& Boshoff, C. 2007. The influence of the owner-manager of small tourism business of internet marketing. South African Business Journal, 38(3):15-27.

Gunasekaran, A. \& Singh, D. 1999. Design of Activity-Based Costing In a Small Company: A Case Study. Computers and Industrial Engineering, 37 (2):413-416.

Johnson, H.T \& Kaplan, R.S. 1987. Relevance lost: The rise and fall of management accounting: Boston: Harvard Business Scholl Press.

Kaplan, R.S., 1988, "One Cost System Isn't Enough", Harvard Business Review, January-February, pp.61-66.

Maree, K. (Editor). 2011. First steps in research. Pretoria: Van Schaik.

Mersereau, K. 2007. Pushing the art of management accounting. Journal of the South African Institute of Professional Accountancy. 10-14.

Mishra, B., and Vaysman, I., 2001 "Cost-system choice and incentives - Traditional Vs Activity-based costing". Journal of Accounting Research, 39(3):619-641.

Morrow, M., and Ashworth, G. 1994, "An Evolving Framework for Activity-Based Approaches", management Accounting (UK), February, pp.2025.

Needy, K.L., Nachtmann, H., Roztocki, N. \& Warner, R.C. 2003. Implementing Activity-Based Costing Systems in Small Manufacturing Firms: A Field Study. Engineering Management Journal, 15(1): 3-10.

Raiborn, C.A, \& Kinney, M.R. 2009. Cost accounting: Foundations and evolutions. Mason: South Western/ Cengage Learning.

Rajasekaran, V., \& Lalitha, R. 2010. Cost Accounting.Pearson Education. India

Swanepoel, J.W.H., Swanepoel, C.J., Van Graan, F.C., Allison, J.S. \& Santana, L. 2010. Elementary statistical methods. Potchefstroom: AndCorp

Terre Blanche, M., Durrheim, K. \& Painter, D. 2006. Research in Practice: Applied methods for social sciences. Cape Town: University of Cape Town Press.

Turney, P. B.B., 1996. Activity-Based Costing: The Performance Breakthrough. London. The Chartered Institute of Management Accounting.

Vaal Information Directory 2013. Retrieved from: www.vaalinfodirectory.co.za

Yellow Pages. (2013). Retrieved from: (http://www.yellowpages.co.za/small_businesses/gauteng/lesedi_rural/small_businesses-lesedi_rural/), (http://www.yellowpages.co.za/small_businesses/gauteng/small_businesses-emfuleni_rural/), and http://www.yellowpages.co.za/small _businesses/gauteng/midvaal/small_businesses-midvaal/

Wegner, T. 2007. Applied business statistics: Methods and Excel-based applications. Cape Town: Juta. 